\title{
In-situ tracking of phase conversion reaction induced metal/metal oxides for efficient oxygen evolution
}

\author{
Shahid Khan ${ }^{1 \dagger}$, Chao Wang ${ }^{1 \dagger}$, Haoliang $\mathrm{Lu}^{1 \dagger}$, Yufeng $\mathrm{Cao}^{3^{*}}$, Zeyang Mao ${ }^{1}$, Chenglin Yan $^{1^{*}}$ and \\ Xianfu Wang ${ }^{2 *}$
}

\begin{abstract}
Due to the unique interface and electronic structure, metal/metal oxide composite electrocatalysts have been designed and exploited for electrocatalytic oxygen evolution reaction (OER) in alkaline solution. However, how to fabricate metal/metal oxides with abundant interfaces and well-dispersed metal phases is a challenge, and the synergistic effect between metal and metal oxides on boosting the electrocatalytic activities is still ambiguous. Herein, by controlling the lithium-induced conversion reaction of metal oxides, metal/metal oxide composites with plentiful interfaces and excellent electrical interconnection are fabricated, which can enhance the active sites, and accelerate the mass transfer during the electrocatalytic reaction. As a result, the electrocatalytic oxygen evolution activities of the as-fabricated metal/ metal oxide composite catalysts including $\mathrm{NiCo} / \mathrm{NiCo}_{2} \mathrm{O}_{4}$, $\mathrm{NiMn} / \mathrm{NiMn}_{2} \mathrm{O}_{4}$ and $\mathrm{CoMn} / \mathrm{CoMn}_{2} \mathrm{O}_{4}$ are greatly improved. The catalytic mechanism is also explored using the in-situ $\mathrm{X}$ ray and Raman spectroscopic tracking to uncover the real active centers and the synergistic effect between the metal and metal oxides during water oxidation. Density functional theory plus $U(D F T+U)$ calculation confirms the metal in the composite can optimize the catalytic reaction path and reduce the reaction barrier, thus boosting the electrocatalytic kinetics.
\end{abstract}

Keywords: in-situ tracking, electrochemical conversion reaction, metal/metal oxide interfaces, electrocatalytic mechanism, oxygen evolution

\section{INTRODUCTION}

Electrochemical water splitting is widely considered to be a critical way for the clean and renewable energy pro- duction, storage and usage such as sustainable hydrogen production, rechargeable metal-air batteries and fuel cells [1-4]. However, owing to the multistep four-electron redox process $\left(4 \mathrm{OH}^{-} \rightarrow 2 \mathrm{H}_{2} \mathrm{O}+4 \mathrm{e}^{-}+\mathrm{O}_{2}\right)$, oxygen evolution reaction (OER) often requires a relatively high overpotential, which leads to the sluggish kinetics and obvious energy loss [5-7]. Though the state-of-the-art precious-metal-based catalysts including $\mathrm{IrO}_{2}$ and $\mathrm{RuO}_{2}$ show impressive OER activities, the scarcity and high cost hinder their scale-up deployment [8-10]. Therefore, it is of great significance to develop earth-abundant transition metals (especially $\mathrm{Fe}, \mathrm{Co}$, and $\mathrm{Ni}$ ) and their derivatives as highly efficient electrocatalysts for oxygen evolution [1122]. Among the non-noble metal-based electrocatalysts, transition metal oxides (TMOs) and layered doublehydroxides (LDHs) have been well designed with satisfying OER activities [23-27]. However, their activity and stability require to be further improved, and in-depth research into the catalytic mechanism of non-noble metal-based electrocatalysts is still lacking.

Rational design of the electrocatalysts can not only increase the active sites, improve the intrinsic activity, but also accelerate the transfer rate of the charge and products, thus obviously boosting electrocatalytic properties. To optimize the activities of the transition-metal-based electrocatalysts, strategies such as heteroatom tailoring, interface engineering, and electronic structure modification have been proposed [28-32]. Metal/metal oxide composites, thanks to the unique two-phase interface and metal-phase-induced desirable electrical conductivity, have been designed and exploited as electrocatalysts re-

\footnotetext{
${ }^{1}$ Soochow Institute for Energy and Materials InnovationS, College of Energy, Soochow University, Suzhou 215006, China

${ }^{2}$ State Key Laboratory of Electronic Thin Films and Integrated Devices, University of Electronic Science and Technology of China, Chengdu 610054, China

${ }^{3}$ School of Chemical and Environmental Engineering, College of Chemistry, Chemical Engineering and Material Science, Soochow University, Suzhou 215123, China

${ }^{\dagger}$ These authors contributed equally to this work.

* Corresponding authors (emails: yufengntu@ntu.edu.cn (Cao Y); c.yan@suda.edu.cn (Yan C); xfwang87@uestc.edu.cn (Wang X))
} 
cently $[33,34]$. For instance, $\mathrm{NiCo} / \mathrm{Fe}_{3} \mathrm{O}_{4}$ heteroparticles with metal-organic frameworks demonstrated remarkable OER activity because $\mathrm{NiCo}$ can stabilize the active oxygen species adsorbed on $\mathrm{Fe}_{3} \mathrm{O}_{4}$ surface [35]. Experimental and theoretical results showed that $\mathrm{MoNi}_{4} / \mathrm{MoO}_{x} @ \mathrm{Ni}$ composite electrocatalyst can effectively reduce the energy barrier of the Volmer step and expedite the hydrogen evolution reaction (HER) kinetics in alkaline solution due to the synergistic effect between $\mathrm{Ni}$ and Mo atoms as well as the improved electron transport [36,37]. However, studies on the OER activities of the metal/metal oxides are seldom and the catalytic mechanism as well as the synergistic effect between the metal and metal oxides on improving the electrocatalytic activities are still indistinct. On the other hand, the interface/boundary in the catalysts plays a key role in the electrocatalytic activities. At the interfaces of metal/metal oxides, metal cations possess positive charge and more unfiled d-orbits, which can facilitate $\mathrm{OH}^{-}$adsorption due to the strong electrostatic interactions. Meanwhile, a nearby metal site would preferentially adsorb $\mathrm{H}$ atom thus boosting the water electrolysis [38]. As a consequence, the methods to fabricate metal/metal oxides with abundant interfaces and welldispersed metal phases are urgently to be developed towards water oxidation.

In-situ electrochemical tuning by lithium insertion/extraction or the conversion reaction is a novel strategy to engineer the electrocatalytic activities of battery electrode materials, such as $\mathrm{LiCoO}_{2}, \mathrm{LiMPO}_{4}(\mathrm{M}=\mathrm{Fe}, \mathrm{Mn}, \mathrm{Co}, \mathrm{Ni})$, $\mathrm{MoS}_{2}$, and $\mathrm{Pd}_{3} \mathrm{P}_{2} \mathrm{~S}_{8}$ [39-44]. For instance, through lithium-induced conversion reaction, ultra-small TMO nanoparticles $(2-5 \mathrm{~nm})$ can be obtained with excellent contact and more active sites, which exhibited high activity and stability for water electrolysis [45]. Distinguished from these studies, we demonstrate that metal oxides with phase conversion mechanism including $\mathrm{NiCo}_{2} \mathrm{O}_{4}, \mathrm{NiMn}_{2} \mathrm{O}_{4}$ and $\mathrm{CoMn}_{2} \mathrm{O}_{4}$ can be in-situ transformed into $\mathrm{NiCo} / \mathrm{NiCo}_{2} \mathrm{O}_{4}, \mathrm{NiMn} / \mathrm{NiMn}_{2} \mathrm{O}_{4}$ and $\mathrm{CoMn} /$ $\mathrm{CoMn}_{2} \mathrm{O}_{4}$ composites using the lithium-induced conversion reaction, which breaks the metal-oxygen bonds and forms metal-metal bonds [46]. The in-situ phaseconversion-induced metal/metal oxides possess plentiful interfaces and excellent electrical interconnection between the metal and metal oxides as well as many catalytically active sites, which are different from traditional chemical syntheses. As a result, the as-optimized $\mathrm{NiCo} /$ $\mathrm{NiCo}_{2} \mathrm{O}_{4}$ composite shows a relatively low overpotential of $264 \mathrm{mV}$ at $10 \mathrm{~mA} \mathrm{~cm}^{-2}$ as well as reduced Tafel slope of $64 \mathrm{mV} \mathrm{dec}^{-1}$ towards water oxidation. Electrocatalytic OER activities of $\mathrm{NiMn} / \mathrm{NiMn}_{2} \mathrm{O}_{4}$ and $\mathrm{CoMn} / \mathrm{CoMn}_{2} \mathrm{O}_{4}$ are also greatly improved compared with $\mathrm{NiMn}_{2} \mathrm{O}_{4}$ and $\mathrm{CoMn}_{2} \mathrm{O}_{4}$, respectively. Real active centers and evolution of the active species were explored using the in-situ X-ray and Raman spectroscopic tracking. The synergistic effect between the metal and metal oxides was also analyzed by density functional theory plus $U(D F T+U)$ calculation. This work not only presents a deeper understanding of the intrinsic mechanism of the metal/metal oxides towards oxygen evolution but also provides a new method to better design earth-abundant composite OER electrocatalysts with high efficiency and stability.

\section{EXPERIMENTAL SECTION}

\section{Materials}

Typically, nickel nitrate hexahydrate $\left(\mathrm{Ni}\left(\mathrm{NO}_{3}\right)_{2} \cdot 6 \mathrm{H}_{2} \mathrm{O}\right.$, $99 \%)$, cobalt nitrate hexahydrate $\left(\mathrm{Co}\left(\mathrm{NO}_{3}\right)_{2} \cdot 6 \mathrm{H}_{2} \mathrm{O}, 99 \%\right)$ and manganese nitrate hexahydrate $\left(\mathrm{Mn}\left(\mathrm{NO}_{3}\right)_{2} \cdot 6 \mathrm{H}_{2} \mathrm{O}\right.$, 99\%) were purchased from Aladdin Ltd. (Shanghai, China). Urea $\left(\mathrm{CO}\left(\mathrm{NH}_{2}\right)_{2}, 99 \%\right)$ and ammonium fluoride $\left(\mathrm{NH}_{4} \mathrm{~F}, 99 \%\right)$ were obtained from Alfa-Aesar, and carbon fiber cloth (CFC) was obtained from Cetech Co. Ltd. All the reagents were used directly without further purification.

\section{Synthesis of $\mathrm{NiCo}_{2} \mathrm{O}_{4}$ nanowire arrays on carbon fiber cloth}

Before the fabrication, $\mathrm{CFC}$ and $\mathrm{Ni}$ foam (NF) were activated with dilute hydrochloric acid by ultrasonic wave for $30 \mathrm{~min}$, and then cleaned in deionized (DI) water and ethanol for $30 \mathrm{~min}$, respectively. In a typical process, $1 \mathrm{mmol} \mathrm{Ni}\left(\mathrm{NO}_{3}\right)_{2} \cdot 6 \mathrm{H}_{2} \mathrm{O}, 2 \mathrm{mmol} \mathrm{Co}\left(\mathrm{NO}_{3}\right)_{2} \cdot 6 \mathrm{H}_{2} \mathrm{O}$, $2 \mathrm{mmol} \mathrm{NH}_{4} \mathrm{~F}$, and $5 \mathrm{mmol}$ urea were dissolved in $35 \mathrm{~mL}$ of distilled water with constant intense stirring to form a homogeneous pink solution. After a piece of cleaned CFC $(2 \mathrm{~cm} \times 3 \mathrm{~cm})$ was put, the solution was then transferred into a Teflon-lined stainless autoclave. The autoclave was sealed and kept at $120^{\circ} \mathrm{C}$ for $6 \mathrm{~h}$. After hydrothermal growth, the CFC covered with NiCo-precursor was carefully rinsed several times with DI water and sonicated to remove the unstable attached materials. After drying at $60^{\circ} \mathrm{C}$ overnight, they were calcined at $400^{\circ} \mathrm{C}$ for $2 \mathrm{~h}$ to obtain the well crystallized $\mathrm{NiCo}_{2} \mathrm{O}_{4}$ nanowires on CFC. After calcination, the mass loading of the $\mathrm{NiCo}_{2} \mathrm{O}_{4}$ nanowires on $\mathrm{CFC}$ was calculated to be about $1.2 \mathrm{mg} \mathrm{cm}^{-2} . \mathrm{NiMn}_{2} \mathrm{O}_{4}$ and $\mathrm{CoMn}_{2} \mathrm{O}_{4}$ samples grown on NFs were obtained by using the similar method. During the hydrothermal process, 150 and $200^{\circ} \mathrm{C}$ were used for the syntheses of $\mathrm{NiMn}_{2} \mathrm{O}_{4}$ and $\mathrm{CoMn}_{2} \mathrm{O}_{4}$ samples, respectively. 


\section{In-situ electrochemical tuning}

The electrochemical tuning process was operated in an electrolytic cell. The as-synthesized $\mathrm{NiCo}_{2} \mathrm{O}_{4}, \mathrm{NiMn}_{2} \mathrm{O}_{4}$ and $\mathrm{CoMn}_{2} \mathrm{O}_{4}$ were used directly as the working electrode, lithium metal foil was used for both the counter and the reference electrode, and $1 \mathrm{~mol} \mathrm{~L}^{-1} \mathrm{LiPF}_{6}$ in ethylene carbonate and diethyl carbonate (EC-DEC, $v / v=$ 1:1) was utilized as the electrolyte. The tuning process was performed in the potential window between 0.5 and $3 \mathrm{~V}$ versus $\mathrm{Li}^{+} / \mathrm{Li}$. Typically, the cycles began with discharge, and the cutoff voltage of the last discharging was $0.5 \mathrm{~V}$. Subsequently, the product was taken out and rinsed with acetone, ethanol and DI water successively.

\section{Materials characterization}

The as-obtained catalysts were characterized by X-ray diffraction (XRD, D8 Advance, Bruker) pattern with a $\mathrm{Cu}$ target $(\mathrm{Ka}, \lambda=0.15406 \mathrm{~nm})$. Scanning electron microscopy (SEM) images of the catalysts were obtained with a JEOL JSM 6700F electron microscope. The morphologies and structures were explored using transmission electron microscope (TEM) and high-resolution TEM (HRTEM, Philips Tecnai F20). Chemical compositions of the prepared catalysts were examined using X-ray photoelectron spectrometer (XPS, Escalab 250Xi, Thermo Fisher). The binding energy was calibrated to the $C 1$ s peak of $284.8 \mathrm{eV}$. In-situ Raman spectra of the electrodes were recorded by using a confocal Raman microscope (HR Evolution, Horiba Jobin Yvon). X-ray absorption near edge structure (XANES) and extended X-ray absorption fine structure (EXAFS) data were collected on beamline $14 \mathrm{~W}$ at Shanghai Synchrotron Radiation Facility (SSRF).

\section{Electrochemical characterizations}

The OER performance was evaluated on WaveDriver 20 bipotentiostat (Pine Instrument Company, USA), using a three-electrode system. CFC substrates coated with $\mathrm{NiCo}_{2} \mathrm{O}_{4}$ or other compositions were directly used as the working electrode. A graphite rod was used as the counter electrode, and an $\mathrm{Ag} / \mathrm{AgCl}$ electrode was used as the reference electrode. $1.0 \mathrm{~mol} \mathrm{~L}^{-1} \mathrm{KOH}$ solution was used as the electrolyte. Linear sweep voltammetry (LSV) was recorded at a scan rate of $1 \mathrm{mV} \mathrm{s}^{-1}$. All potentials reported were calibrated to reversible hydrogen electrode (RHE) through the equation $E_{\mathrm{RHE}}=E_{\mathrm{Ag} / \mathrm{AgCl}}+0.197 \mathrm{~V}+0.0591 \times$ $\mathrm{pH}$. Electrochemical impedance spectroscopy (EIS) for the NiCo-based catalysts was measured at the voltage to reach $10 \mathrm{~mA} \mathrm{~cm}^{-2}$. EIS for NiMn- and CoMn-based catalysts were measured at the voltage to reach $100 \mathrm{~mA} \mathrm{~cm}{ }^{-2}$. The mass loading of the $\mathrm{NiCo}_{2} \mathrm{O}_{4}$, the products after the first and third discharge (denoted as the 1 st and $3 \mathrm{rd} \mathrm{NiCo} / \mathrm{NiCo}_{2} \mathrm{O}_{4}$ ) on CFC were weighed to be about $1.2 \mathrm{mg} \mathrm{cm}^{-2}$. In order to accurately calculate the catalyst loading, we used inductively coupled plasma mass spectrometry (ICP-MS) to measure the mass of the metal active material on the $1 \mathrm{~cm}^{2}$ electrode, and the results are shown in Table S1. All the polarization curves were obtained with ohmic potential drop (iR) correction. The turnover frequency (TOF) values were calculated according to the following equation: TOF $=J \times A / 4 \times F \times$ $m$, where $J$ is the current density, $A$ is the area of the effective CFC $\left(1 \mathrm{~cm}^{2}\right), F$ is the Faraday constant (a value of $96,485 \mathrm{C} \mathrm{mol}^{-1}$ ), $m$ is the number of moles of the active materials that deposited onto the carbon fiber paper.

\section{In situ Raman spectroscopy}

The in-situ Raman spectra were obtained by a confocal Raman microscope (HR Evolution, Horiba Jobin Yvon). A custom-made poly(tetra fluoroethylene) (PTFE) electrochemical cell assembled with a graphite rod counter electrode, $\mathrm{Ag} / \mathrm{AgCl}$ electrode as the reference electrode and $1.0 \mathrm{~mol} \mathrm{~L}^{-1} \mathrm{KOH}$ electrolyte was used for Raman experiments. And $\mathrm{NiCo}_{2} \mathrm{O}_{4} / \mathrm{CFC}$ was used as the working electrode directly. Amperometric i- $t$ curves (CHI 660E, Shanghai Chenhua instrument Co. Ltd) under various potentials were carried out to deduce the OER. Spectra were acquired under laser excitation with wavelength of $633 \mathrm{~nm}$.

\section{RESULTS AND DISCUSSION}

$\mathrm{NiCo}_{2} \mathrm{O}_{4}$ nanowire arrays on CFC were firstly prepared to explore the geometry and OER activity evolutions upon the lithium-induced conversion reaction. The in-situ electrochemical tuning process is illustrated in Fig. 1a, in which the as-synthesized $\mathrm{NiCo}_{2} \mathrm{O}_{4}$ nanowire array is used as the anode and a lithium plate serves as the counter electrode. Upon the electrochemical lithiation, highvalence nickel and cobalt species are reduced and $\mathrm{NiCo}$ can be obtained when discharged to $1.0 \mathrm{~V} \mathrm{vs.} \mathrm{Li}^{+} / \mathrm{Li}$ due to the conversion reaction mechanism of the spinel $\mathrm{NiCo}_{2} \mathrm{O}_{4}$ electrode $[46,47]$. As well known, the full transformation of metal oxides into metal requires a relatively slow ion-diffusion rate and a necessary activation process during the first several charge-discharge cycles. In our operation, to obtain the $\mathrm{NiCo} / \mathrm{NiCO}_{2} \mathrm{O}_{4}$ hybrid product, a relatively high current density of $1000 \mathrm{~mA} \mathrm{~cm}^{-2}$ was adopted. By regulating the charge-discharge cycles, the contents of $\mathrm{NiCo}$ and $\mathrm{NiCo}_{2} \mathrm{O}_{4}$ can also be controlled to optimize their electrocatalytic activities. Upon the lithiation, NiCo nanocrystallines are in-situ generated on 

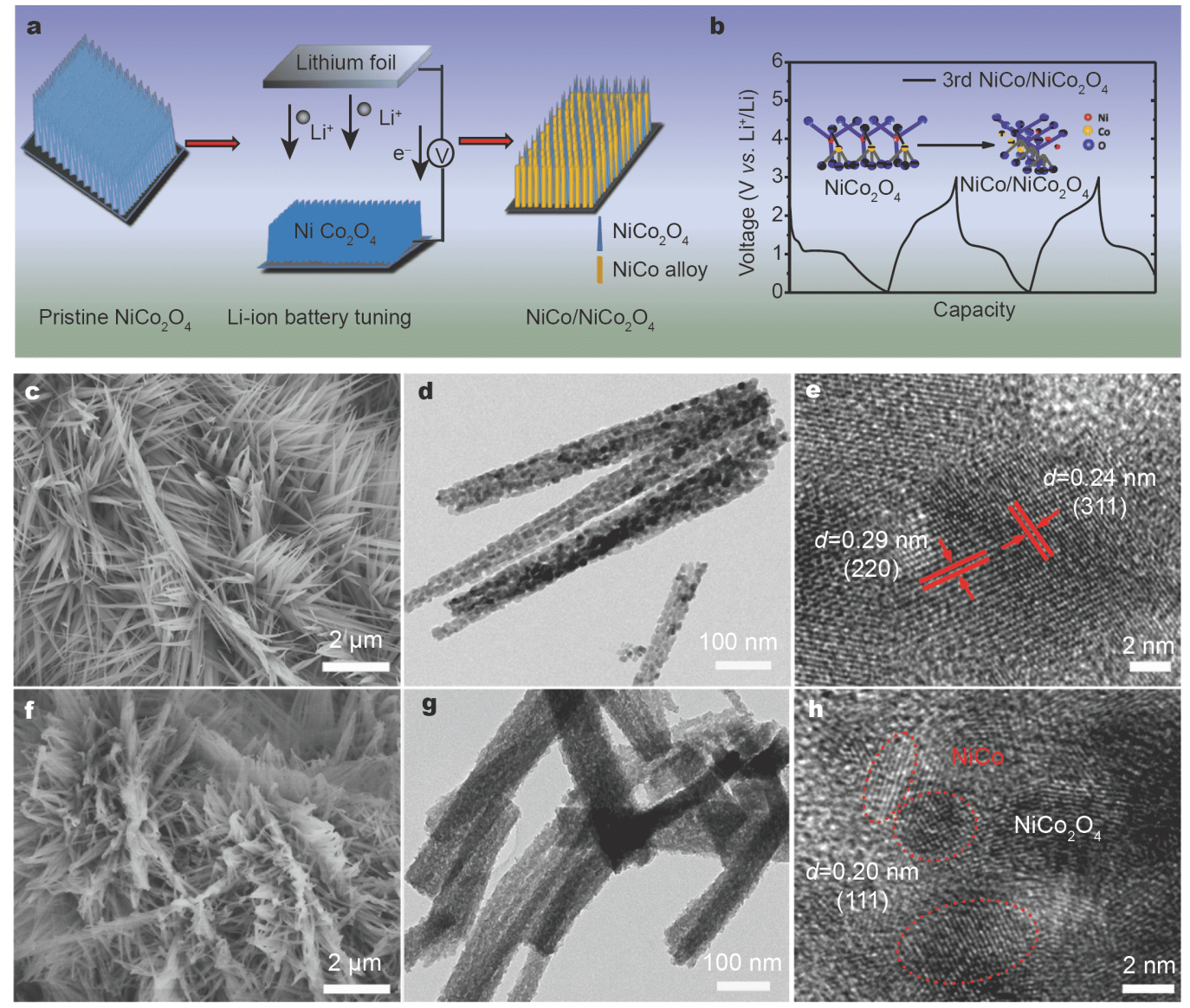

Figure 1 (a) Schematic of the in-situ electrochemical tuning process. (b) Galvanostatic cycling profiles of $\mathrm{NiCo}_{2} \mathrm{O}_{4}$ at $1000 \mathrm{~mA} \mathrm{~cm}$. (c) SEM, (d) TEM, and (e) HRTEM images of $\mathrm{NiCo}_{2} \mathrm{O}_{4}$. (f) SEM, (g) TEM, and (h) HRTEM images of the $3 \mathrm{rd} \mathrm{NiCo} / \mathrm{NiCo}_{2} \mathrm{O}_{4}$.

$\mathrm{NiCo}_{2} \mathrm{O}_{4}$ matrix combined with plentiful interfaces and excellent electrical interconnection, which would highly accelerate the charge transfer and increase the catalytic active sites. Fig. $1 \mathrm{~b}$ shows the galvanostatic cycling profiles of the $\mathrm{NiCo}_{2} \mathrm{O}_{4}$ electrode. To ensure the hybrid product of $\mathrm{NiCo} / \mathrm{NiCo}_{2} \mathrm{O}_{4}$ composite, a cutoff potential of $0.5 \mathrm{~V} v s . \mathrm{Li}^{+} / \mathrm{Li}$ that below the conversion reaction was selected for the discharge. Furthermore, to maintain the micro-structure of the nanowire arrays and explore the effect of $\mathrm{NiCo} / \mathrm{NiCo}_{2} \mathrm{O}_{4}$ ratio on the electrocatalytic activities, the 1 st and $3 \mathrm{rd} \mathrm{NiCo} / \mathrm{NiCo}_{2} \mathrm{O}_{4}$ were studied.

$\mathrm{XRD}$ result of the as-synthesized product (Fig. S1) indexes well with the standard pattern of PDF card. 200781, indicating pristine spinel $\mathrm{NiCo}_{2} \mathrm{O}_{4}$ phase was obtained. After the lithium-induced conversion reaction, some new characteristic peaks of $\mathrm{Ni}$ and $\mathrm{Co}$ appeared, and the diffraction peaks can be indexed well with the standard patterns of Ni (JCPDS No. 04-0850) and Co (JCPDS No. 15-0806), demonstrating the successful synthesis of $\mathrm{NiCo} / \mathrm{NiCo}_{2} \mathrm{O}_{4}$. Fig. S2 and Fig. 1c show the scanning electron microscopy (SEM) images of the asprepared $\mathrm{NiCo}_{2} \mathrm{O}_{4}$ electrode, where $\mathrm{NiCo}_{2} \mathrm{O}_{4}$ nanowire arrays are uniformly distributed on the CFC. Instead of the conventional single-crystalline nanowire, as displayed in the TEM image (Fig. 1d), the $\mathrm{NiCo}_{2} \mathrm{O}_{4}$ nanowires are assembled by a number of nanoparticles, forming a mesoporous structure with highly exposed active sites for electrocatalysis. Two sets of lattice fringes with spacing of 0.29 and $0.24 \mathrm{~nm}$ can be observed in the HRTEM image shown in Fig. 1e, which correspond well to d-spacing of the (220) and (311) planes in spinel $\mathrm{NiCo}_{2} \mathrm{O}_{4}$, respectively, further confirming the as-well synthesized $\mathrm{NiCO}_{2} \mathrm{O}_{4}$ nanowires.

After the electrochemical tuning, binary transition $\mathrm{NiCo} / \mathrm{NiCo}_{2} \mathrm{O}_{4}$ composite with engineered microstructure was obtained. SEM images clearly reveal that the $\mathrm{NiCo} / \mathrm{NiCo}_{2} \mathrm{O}_{4}$ hybrid product after three discharge/ charge cycles still maintains the nanowire architecture (Fig. If and Fig. S3). Obviously, lithiation-induced volume expansion of the $\mathrm{NiCo}_{2} \mathrm{O}_{4}$ nanowires can be found 
from the TEM image (Fig. 1g). In addition, due to the electrochemical conversion reaction, more nano interfaces are expected to be generated between the newly formed $\mathrm{NiCo}$ and the $\mathrm{NiCo}_{2} \mathrm{O}_{4}$ matrix, which has been evidenced as the additional active sites for OER [48]. Furthermore, because of the irreversible decomposition of $\mathrm{NiCo}_{2} \mathrm{O}_{4}\left(\mathrm{NiCo}_{2} \mathrm{O}_{4}+8 \mathrm{Li}^{+}+8 \mathrm{e}^{-} \rightarrow \mathrm{Ni}+2 \mathrm{Co}+4 \mathrm{Li}_{2} \mathrm{O}\right)$ and oxide reorganization during the cycling process, the $\mathrm{NiCo} / \mathrm{NiCo}_{2} \mathrm{O}_{4}$ nanowires have a more disordered structure with rough and loose surface. As a result, the 3rd $\mathrm{NiCo} / \mathrm{NiCo}_{2} \mathrm{O}_{4}$ sample shows smaller chaotic grains (Fig. 1h), well consistent with the previous report [45]. Apart from the lattice fringe of $\mathrm{NiCo}_{2} \mathrm{O}_{4}$ matrix, the lattice distance of $0.2 \mathrm{~nm}$ (red circle area) corresponds well with the d-spacing of the (111) crystallographic planes of cubic $\mathrm{NiCo}$, strongly confirming the generation of $\mathrm{NiCo}$ after the phase conversion reaction. These observations indicate that, by taking use of the lithium-induced electrochemical conversion reaction, binary transition metal/ metal oxide composites can be achieved with smaller grain size, more grain boundaries/interfaces, and excellent electrical interconnection, which are beneficial to the electrocatalytic activity toward oxygen evolution.

XPS was used to analyze the element composition and surface chemical state of the as-prepared composite catalysts. The $\mathrm{NiCo} / \mathrm{NiCO}_{2} \mathrm{O}_{4}$ samples still consist of $\mathrm{Ni}$, Co and $\mathrm{O}$ without introducing other new elements (Fig. S4) since it is just the conversion reaction that happens during the electrochemical tuning process. Fig. 2a shows

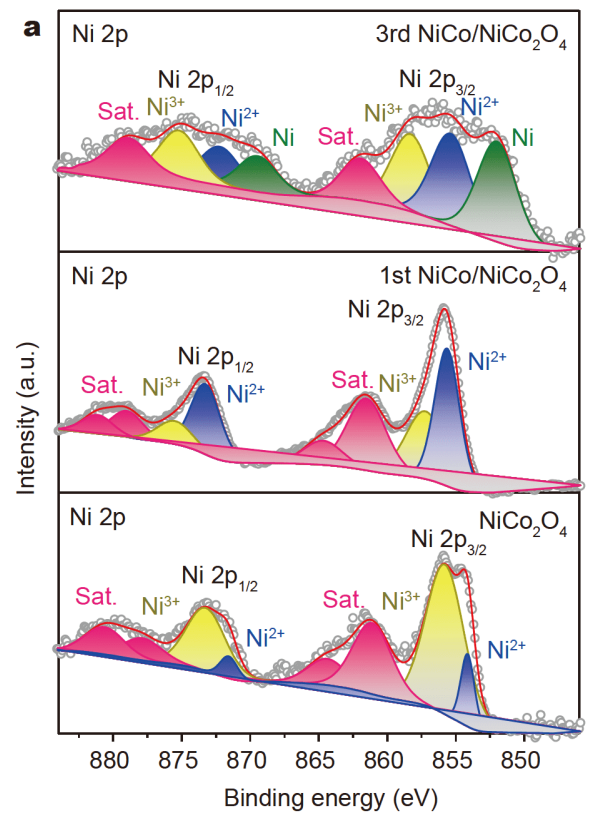

the high-resolution $\mathrm{Ni} 2 \mathrm{p}$ spectra of $\mathrm{NiCo}_{2} \mathrm{O}_{4}$, the 1st and 3rd $\mathrm{NiCo} / \mathrm{NiCo}_{2} \mathrm{O}_{4}$. They consist of two prominent $\mathrm{Ni} 2 \mathrm{p}_{3 / 2}$ and $\mathrm{Ni} 2 \mathrm{p}_{1 / 2}$ peaks with each satellite peak. As for the pristine $\mathrm{NiCo}_{2} \mathrm{O}_{4}$, the $\mathrm{Ni} 2 \mathrm{p}_{3 / 2}$ portion can be divided into two peaks located at 854.2 and $855.8 \mathrm{eV}$, indicating the presence of $\mathrm{Ni}^{2+}$ and $\mathrm{Ni}^{3+}$ species. Similarly, the peaks centered at 871.6 and $873.2 \mathrm{eV}$ are assigned to the $\mathrm{Ni}^{2+} 2 \mathrm{p}_{1 / 2}$ and $\mathrm{Ni}^{3+} 2 \mathrm{p}_{1 / 2}$, respectively [49]. Different from the pristine $\mathrm{NiCo}_{2} \mathrm{O}_{4}$, the signal of $\mathrm{Ni}^{3+}$ species clearly weakens after the first discharge, demonstrating the reduction of the high-valence $\mathrm{Ni}$ species during the lithiation. In addition, the binding energy are upshifted, revealing the engineered electronic structure. The content of low-valence $\mathrm{Ni}$ species increases with the charge/discharge cycles. As evidenced from the Ni 2p XPS spectrum of the $3 \mathrm{rd} \mathrm{NiCo} / \mathrm{NiCo}_{2} \mathrm{O}_{4}$, additional two peaks centered at 852.5 and $869 \mathrm{eV}$ associated with the zerovalent $\mathrm{Ni}$ obviously appear [40]. Besides, the binding energy of $\mathrm{Ni}^{2+}$ species in the 1st and 3rd discharged products shifts to a higher value of $855.7 \mathrm{eV}$, demonstrating the formation of $\mathrm{Ni}(\mathrm{OH})_{2}$ on the surface of $\mathrm{NiCo} / \mathrm{NiCo}_{2} \mathrm{O}_{4}$ [50]. The insitu generated $\mathrm{Ni}^{0}$ in $\mathrm{NiCo} / \mathrm{NiCo}_{2} \mathrm{O}_{4}$ is easily oxidized to $\mathrm{Ni}(\mathrm{OH})_{2}$ upon exposing to air, which also contributes to the $\mathrm{Ni}^{2+}$ species on the surface detected from XPS with larger binding energy than that in the pure $\mathrm{NiCo}_{2} \mathrm{O}_{4}[51]$. The existence of these $\mathrm{Ni}^{2+}$ species is conducive to attracting hydrated ions onto the catalyst surface, thus promoting the decomposition of water molecules and accelerating the oxygen evolution.

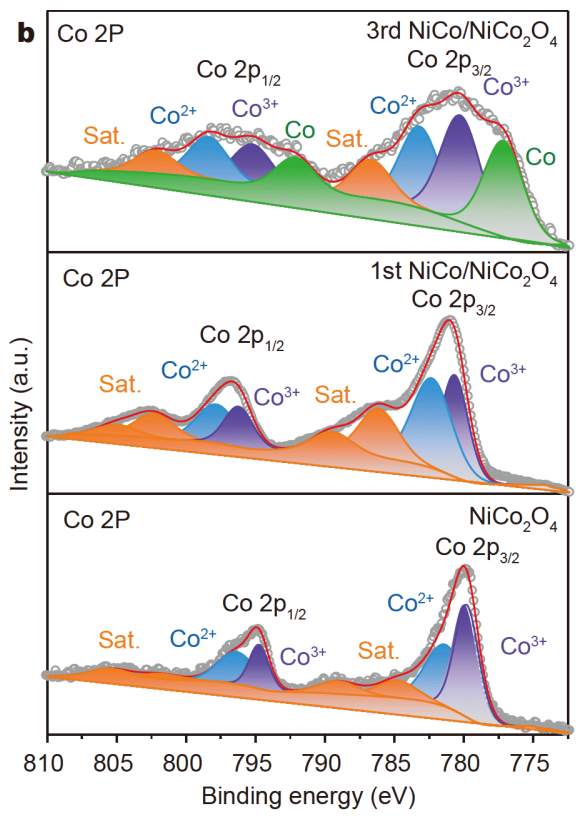

Figure 2 High-resolution XPS spectra of (a) $\mathrm{Ni} 2 \mathrm{p}$ and (b) $\mathrm{Co} 2 \mathrm{p}$ in $\mathrm{NiCo}_{2} \mathrm{O}_{4}$, the 1 st and $3 \mathrm{rd} \mathrm{NiCo} / \mathrm{NiCo}_{2} \mathrm{O}_{4}$. 
Fig. $2 \mathrm{~b}$ shows the Co $2 \mathrm{p}$ XPS spectra of the products. Both $\mathrm{Co}^{2+}$ and $\mathrm{Co}^{3+}$ species can be found in the as-prepared pristine $\mathrm{NiCo}_{2} \mathrm{O}_{4}$ nanowires. The content of $\mathrm{Co}^{3+}$ species decreases for the 1 st $\mathrm{NiCo} / \mathrm{NiCo}_{2} \mathrm{O}_{4}$ composite, revealing high-valence $\mathrm{Co}$ species is reduced during the first discharge. For the $3 \mathrm{rd} \mathrm{NiCo} / \mathrm{NiCo}_{2} \mathrm{O}_{4}$ composite, two peaks associated with zerovalent $\mathrm{Co}$ can be observed with binding energy of 777.5 and $792.8 \mathrm{eV}$. It is worth to note that the peaks for $\mathrm{Co}^{2+} 2 \mathrm{p}$ and $\mathrm{Co}^{3+} 2 \mathrm{p}$ shift to higher binding energy, demonstrating the engineered electronic structure of the $\mathrm{NiCo}_{2} \mathrm{O}_{4}$ after the in-situ electrochemical tuning operation, which keeps well with the Ni 2p XPS analysis. Fig. S5 shows the O 1s spectra of the samples. Obviously, the peaks shift to higher binding energy upon the charge/discharge cycles, further confirming the tai-

lored electronic structure. The peak at $531.8 \mathrm{eV}$ for the 3rd $\mathrm{NiCo} / \mathrm{NiCo}_{2} \mathrm{O}_{4}$ is associated with lattice oxygen, and the other two peaks located at 533.8 and $535.3 \mathrm{eV}$ correspond to adsorbed oxygen [52]. Based on these results, we can conclude that $\mathrm{NiCo} / \mathrm{NiCo}_{2} \mathrm{O}_{4}$ hybrid product can be obtained exploiting the lithium-induced electrochemical conversion reaction of $\mathrm{NiCO}_{2} \mathrm{O}_{4}$.

To evaluate the electrochemical OER catalytic activities, the $\mathrm{NiCo} / \mathrm{NiCo}_{2} \mathrm{O}_{4}$ nanowires were tested in a standard three-electrode system. Fig. 3a shows the polarization curves of the $\mathrm{NiCo}_{2} \mathrm{O}_{4}$, the 1 st and $3 \mathrm{rd} \mathrm{NiCo} / \mathrm{NiCo}_{2} \mathrm{O}_{4}$ in $1.0 \mathrm{~mol} \mathrm{~L}^{-1} \mathrm{KOH}$ solution at a scan rate of $1 \mathrm{mV} \mathrm{s}^{-1}$. As can be seen, the 1 st and $3 \mathrm{rd} \mathrm{NiCo} / \mathrm{NiCo}_{2} \mathrm{O}_{4}$ present much higher currents than pure $\mathrm{NiCo}_{2} \mathrm{O}_{4}$ at a constant potential, indicating the improved electrocatalytic OER activ-
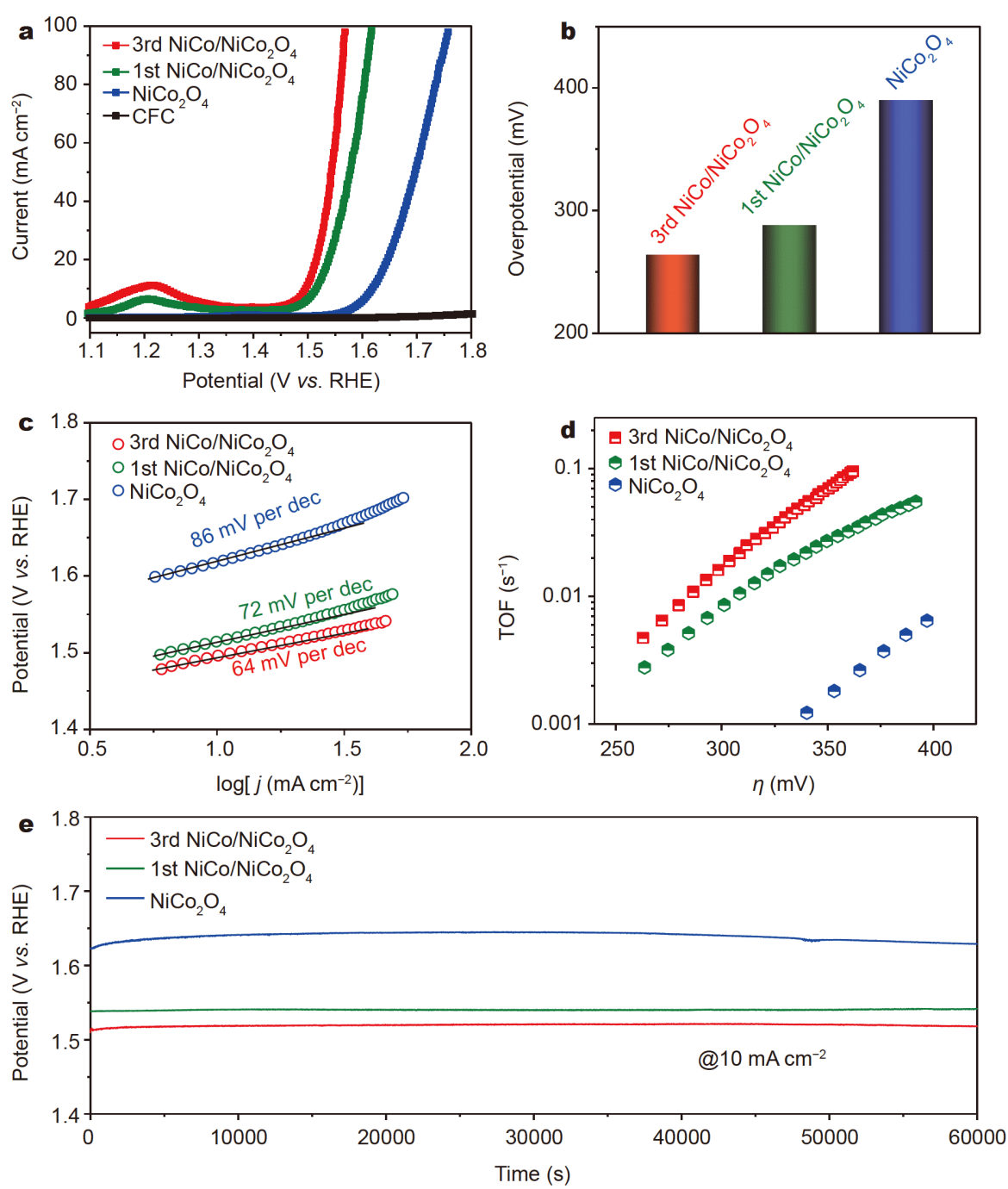

Figure 3 Electrocatalytic OER performance of $\mathrm{NiCo}_{2} \mathrm{O}_{4}$, the 1st and $3 \mathrm{rd} \mathrm{NiCo} / \mathrm{NiCo}_{2} \mathrm{O}_{4}$. (a) LSV polarization curves with iR correction. (b) Overpotential required for $10 \mathrm{~mA} \mathrm{~cm}^{-2}$. (c) Tafel plots, (d) TOF at different overpotentials, and (e) chronopotentiometric curves obtained at $10 \mathrm{~mA} \mathrm{~cm}^{-2}$. 
ities. Oxidation peak appears during the polarization for the $\mathrm{NiCo} / \mathrm{NiCo}_{2} \mathrm{O}_{4}$ catalysts, which can be ascribed to oxidation of the lower-valence $\mathrm{Ni}$ species including $\mathrm{Ni}^{0}$ and $\mathrm{Ni}^{2+}$ which are more easily oxidized in the electrocatalytic process. Importantly, the $3 \mathrm{rd} \mathrm{NiCo} / \mathrm{NiCO}_{2} \mathrm{O}_{4}$ exhibits much better OER performance than the 1st $\mathrm{NiCo} / \mathrm{NiCo}_{2} \mathrm{O}_{4}$, owing to the increased charge transfer capacity and active sites resulting from the metal/metal oxides interface along with the galvanostatic cycles. As revealed in Fig. $3 \mathrm{~b}$, the $3 \mathrm{rd} \mathrm{NiCo} / \mathrm{NiCo}_{2} \mathrm{O}_{4}$ catalyst requires a very low overpotential of $264 \mathrm{mV}$ to reach a current density of $10 \mathrm{~mA} \mathrm{~cm}^{-2}$, which is much lower than that of the 1st $\mathrm{NiCo} / \mathrm{NiCo}_{2} \mathrm{O}_{4}(288 \mathrm{mV})$ and $\mathrm{NiCo}_{2} \mathrm{O}_{4}$ (390 mV).

Tafel slopes were also calculated from the polarization curves to further clarify the enhanced electrocatalytic kinetics. As displayed in Fig. $3 \mathrm{c}$, the $3 \mathrm{rd} \mathrm{NiCo} / \mathrm{NiCo}_{2} \mathrm{O}_{4}$ presents the lowest Tafel slope of $64 \mathrm{mV} \mathrm{dec}^{-1}$ among these catalysts, indicating the increased OER kinetics due to the improved mass transfer rate associated with the generated $\mathrm{NiCo}$ and the $\mathrm{NiCo} / \mathrm{NiCo}_{2} \mathrm{O}_{4}$ interface, which can be further confirmed by the decreased charge-transfer resistances of the $\mathrm{NiCo} / \mathrm{NiCo}_{2} \mathrm{O}_{4}$ samples (Fig. S6). The quantification of each active site was considered by calculating the TOF values, to gain further insight into the improved OER activities of the $\mathrm{NiCo} / \mathrm{NiCo}_{2} \mathrm{O}_{4}$ composite catalysts. As expected, the smaller nanoparticles and rich nano-interfaces produced after the conversion reaction possess more boundaries and dislocations, which can act as the active sites to enhance the catalytic efficiency [53]. These changes can be reflected in the TOF values by an order of magnitude increase. As demonstrated in Fig. 3d, the $3 \mathrm{rd} \mathrm{NiCo} / \mathrm{NiCo}_{2} \mathrm{O}_{4}$ shows a TOF value of $0.021 \mathrm{~s}^{-1}$ at an overpotential of $350 \mathrm{mV}$, which is more than 8 -fold higher than that of the $\mathrm{NiCo}_{2} \mathrm{O}_{4}$ catalyst $\left(0.00265 \mathrm{~s}^{-1}\right)$, revealing the higher intrinsic activity of the $\mathrm{NiCo} /$ $\mathrm{NiCo}_{2} \mathrm{O}_{4}$ composite catalyst. The long-term electrolysis stability of the catalysts was further evaluated by testing the potential stability to keep a constant current density of $10 \mathrm{~mA} \mathrm{~cm}^{-2}$. Moreover, the double-layer capacitance $\left(C_{\mathrm{dl}}\right)$ was evaluated to compare the electrochemical surface areas (ECSAs) of the catalysts. The $2 C_{\mathrm{dl}}$ value of the $3 \mathrm{rd} \mathrm{NiCo} / \mathrm{NiCo}_{2} \mathrm{O}_{4}$ was calculated to be $119.8 \mathrm{mF} \mathrm{cm}$ (Fig. S7), which is two times larger than that of the pure $\mathrm{NiCo}_{2} \mathrm{O}_{4}$, demonstrating the increased ECSA induced by the conversion reaction, which provides more exposed active sites for the promotion of OER activity. Impressively, the 1st and $3 \mathrm{rd} \mathrm{NiCo} / \mathrm{NiCo}_{2} \mathrm{O}_{4}$ show a stable overpotential after $60,000 \mathrm{~s}$ without obvious degradation, confirming their remarkable OER catalytic activity and stability. XRD in Fig. S1b and TEM images in Fig. S8 of the $3 \mathrm{rd} \mathrm{NiCo} / \mathrm{NiCo}_{2} \mathrm{O}_{4}$ after OER tests show that the catalyst is very robust without any phase and structural damage. The $\mathrm{Ni}^{0}$ and $\mathrm{Co}^{0}$ characteristic peaks in XPS spectra of the $3 \mathrm{rd} \mathrm{NiCo} / \mathrm{NiCo}_{2} \mathrm{O}_{4}$ after the OER reaction (Fig. S9) are slightly weakened, which can be attributed to the oxidation of some zero-valent $\mathrm{Ni}$ and Co during the OER process.

Operando techniques were performed to identify the actual electrocatalytic active centers of the $\mathrm{NiCo} / \mathrm{NiCo}_{2} \mathrm{O}_{4}$ composite catalyst. In-situ X-ray absorption spectroscopy (XAS) studies were first conducted to directly monitor the electronic and geometric structure evolution of electrocatalysts during the electrocatalytic OER process. Fig. $4 \mathrm{a}, \mathrm{b}$ show the XANES spectra at the Ni K-edge and Co K-edge under the altered potentials. When the $\mathrm{NiCo} /$ $\mathrm{NiCo}_{2} \mathrm{O}_{4}$ composite was soaked into the $1 \mathrm{~mol} \mathrm{~L}^{-1} \mathrm{KOH}$ solution at open circuit, no obvious structural change was observed from the Ni K-edge spectrum as compared with the sample in air. Then the absorption edge continuously moves to higher energy with increasing applied potential, illustrating the oxidation of $\mathrm{Ni}^{2+}$ ions to higher oxidation state, namely $\mathrm{NiOOH}$ phase which contains a mixture of $\mathrm{Ni}^{3+}$ and $\mathrm{Ni}^{4+}$ species [52-54]. The gradual decreasing intensity of the white-line peak in the Ni K-edge spectrum proved that the geometric structure of the catalyst has been evolved from crystal into a distorted structure upon oxidation $[53,55]$. More importantly, the potentialdependent process is reversible, as the applied potential is back to $0 \mathrm{~V}$, the Ni K-edge spectrum returns to its initial low energy state. This evidences that nickel ions in the $\mathrm{NiCo} / \mathrm{NiCo}_{2} \mathrm{O}_{4}$ catalyst are able to be readily oxidized to high valence, thus exhibiting more reactivity and should be the electrocatalytic active centers for oxygen evolution. Surprisingly, the features of Co K-edge absorption spectra are not obviously affected by the increasing potential from 0 to $0.45 \mathrm{~V} v s$. $\mathrm{Ag} / \mathrm{AgCl}$, revealing Co maintains as the mixture of $\mathrm{Co}^{2+} / \mathrm{Co}^{3+}$ during oxygen evolution [56]. The feeble change of the peak intensity after soaking into the solution may be attributed to the formation of hydrates. Consequently, the XAS data reveal the fact that the nickel ions in $\mathrm{NiCo} / \mathrm{NiCo}_{2} \mathrm{O}_{4}$ composite are the realistic active species.

To further explore the active phase and key intermediates during the OER process, in-situ Raman spectra were recorded from 0 to $0.7 \mathrm{~V}$ vs. $\mathrm{Ag} / \mathrm{AgCl}$. Fig. $4 \mathrm{c}$, d compare the operando Raman spectroscopy of the pure $\mathrm{NiCo}_{2} \mathrm{O}_{4}$ and the $3 \mathrm{rd} \mathrm{NiCo} / \mathrm{NiCo}_{2} \mathrm{O}_{4}$ composite during OER. The local structure for these catalysts under potentials between 0 and $0.1 \mathrm{~V} v s$. $\mathrm{Ag} / \mathrm{AgCl}$ can be ascribed 

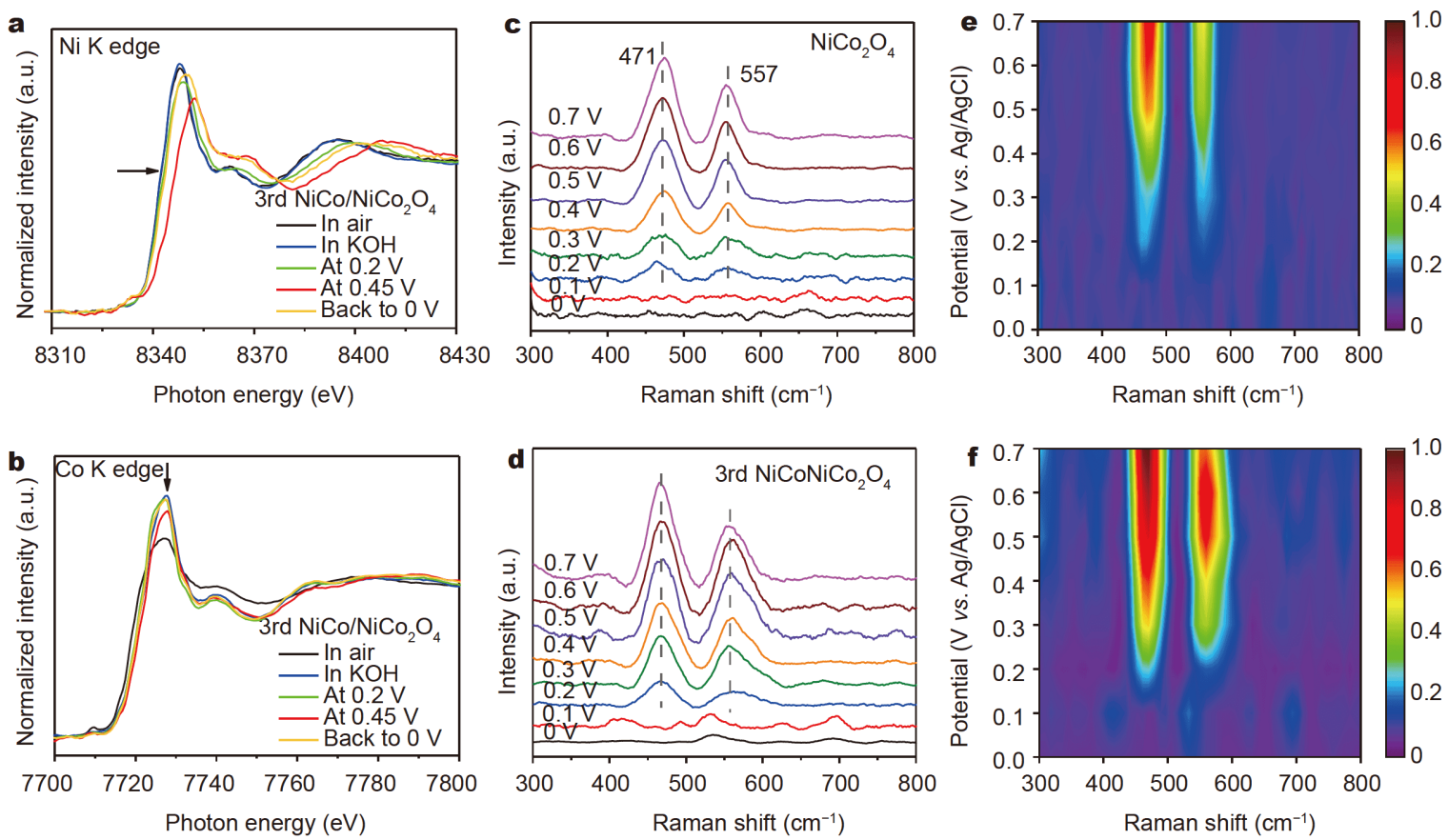

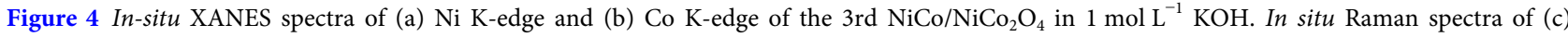
$\mathrm{NiCo}_{2} \mathrm{O}_{4}$ and $(\mathrm{d})$ the $3 \mathrm{rd} \mathrm{NiCo} / \mathrm{NiCo}_{2} \mathrm{O}_{4}$, and the corresponding normalized intensity maps of (e) $\mathrm{NiCo}_{2} \mathrm{O}_{4}$ and $(\mathrm{f})$ the $3 \mathrm{rd} \mathrm{NiCo} / \mathrm{NiCo}_{2} \mathrm{O}_{4}$ under different applied potentials $v s$. $\mathrm{Ag} / \mathrm{AgCl}$ (without iR correction).

to the local spinel structure of $\mathrm{NiCO}_{2} \mathrm{O}_{4}$ with characteristic phonon modes at 455,526 , and $657 \mathrm{~cm}^{-1}[56,57]$. As the potential is swept anodically to $0.2 \mathrm{~V} v s$. $\mathrm{Ag} / \mathrm{AgCl}$, significant structural transformation is observed. The primary three peaks disappeared and new peaks at 471 and $557 \mathrm{~cm}^{-1}$ emerged for the pure $\mathrm{NiCo}_{2} \mathrm{O}_{4}$ catalyst. The pair of new peaks are attributed to the $\mathrm{E}_{\mathrm{g}}$ bending vibration and the $\mathrm{A}_{1 \mathrm{~g}}$ stretching vibration of $\mathrm{Ni}-\mathrm{O}$ in $\mathrm{NiOOH}$ [58], demonstrating the Ni species in the catalyst have been transformed into oxyhydroxides under water oxidation potential. The $3 \mathrm{rd} \mathrm{NiCo} / \mathrm{NiCo}_{2} \mathrm{O}_{4}$ composite shows similar structural evolution with increasing anodic polarization from 0.2 to $0.7 \mathrm{~V} v s$. $\mathrm{Ag} / \mathrm{AgCl}$ but with higher intensity under the same potential. As a consequence, in-situ Raman characterization confirms the transformation from low-valence Ni species to high-valence $\mathrm{NiOOH}$, which plays a key role in the OER process. Moreover, the relative intensities of the Raman double bands associated with the generated $\mathrm{NiOOH}$ on the $\mathrm{NiCo} / \mathrm{NiCo}_{2} \mathrm{O}_{4}$ are further clearly confirmed to be much stronger compared with those of the pure $\mathrm{NiCo}_{2} \mathrm{O}_{4}$ sample (Fig. 4e, f). This result allows for the conclusion that the in-situ electrochemical-conversion-induced NiCo combined with the formed $\mathrm{Ni}(\mathrm{OH})_{2}$ on the surface of the composite benefit the electrocatalytic activities of
$\mathrm{NiCO}_{2} \mathrm{O}_{4}$ catalyst for OER.

DFT + U calculation was performed to well investigate the $\mathrm{NiCo} / \mathrm{NiCo}_{2} \mathrm{O}_{4}$ interface effect on the electrocatalytic OER activity. We considered $\mathrm{Ni}$ sites on the $\mathrm{NiCo}$ (111), $\mathrm{NiCo}_{2} \mathrm{O}_{4}$ (100) planes and their interface due to their similar d-spacing of about $0.2 \mathrm{~nm}$ (Figs S10-S12). As demonstrated by the free energy diagrams (Fig. S13), the potential limiting step is to form $\mathrm{OOH}$ for the NiCo (111) surface. While on the $\mathrm{NiCo}_{2} \mathrm{O}_{4}$ (100) plane, the step with the release of $\mathrm{O}_{2}$ shows the largest reaction barrier (Fig. S14), and the calculated overpotential is much lower than that of the NiCo (111) surface. Interestingly, the determining step on the $\mathrm{NiCo}(111) / \mathrm{NiCo}_{2} \mathrm{O}_{4}(100)$ interface becomes the production of ${ }^{*} \mathrm{OOH}$ species again $(1.56 \mathrm{eV})$, and the calculated overpotential is reduced to $330 \mathrm{mV}$ (Fig. S15), which results in the accelerated OER kinetics with lowered Tafel slope and decreased charge transfer resistance of the $\mathrm{NiCo} / \mathrm{NiCO}_{2} \mathrm{O}_{4}$ composite catalyst [35]. These experimental and theoretical analyses further confirm the NiCo in the composite can optimize the catalytic reaction path and reduce the reaction barrier, thus expediting the electrocatalytic kinetics.

Lithium-induced phase conversion reaction can also be used to convert other metal oxides into metal/metal oxide composite electrocatalysts. Fig. S16 displays the micro- 

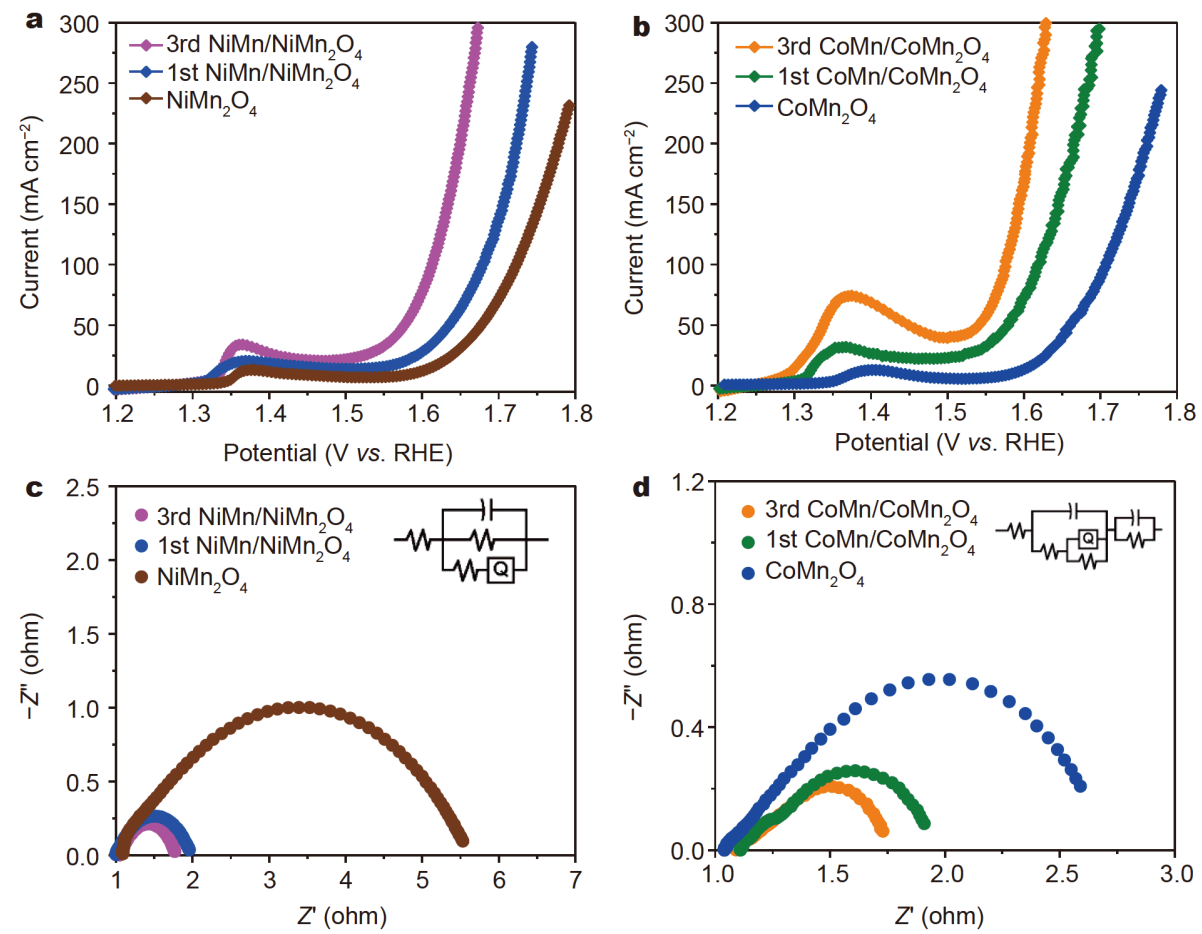

Figure 5 LSV polarization curves of (a) $\mathrm{NiMn}_{2} \mathrm{O}_{4}$ and (b) $\mathrm{CoMn}_{2} \mathrm{O}_{4}$ composites. Nyquist plots of (c) $\mathrm{NiMn}_{2} \mathrm{O}_{4}$ and (d) CoMn $\mathrm{O}_{4}$ composites.

structures of the as-prepared $\mathrm{NiMn}_{2} \mathrm{O}_{4}$ and $\mathrm{CoMn}_{2} \mathrm{O}_{4}$ on NF. After discharge, valence states of the metal cations are reduced and a certain amount of metallic $\mathrm{Ni}, \mathrm{Mn}$, and Co can be detected (Figs S17, S18), indicating NiMn/ $\mathrm{NiMn}_{2} \mathrm{O}_{4}$ and $\mathrm{CoMn} / \mathrm{CoMn}_{2} \mathrm{O}_{4}$ composites are successfully obtained, respectively, after the electrochemical conversion reaction. Compared with the matal oxides, the as-fabricated metal/metal oxide composites exhibit improved OER activities. As shown in Fig. 5a, b, to deliver a current density of $100 \mathrm{~mA} \mathrm{~cm}{ }^{-2}, \mathrm{NiMn}_{2} \mathrm{O}_{4}$ and $\mathrm{CoMn}_{2} \mathrm{O}_{4}$ require overpotentials of 500 and $477 \mathrm{mV}$, respectively, which are reduced to 384 and $345 \mathrm{mV}$ after the third discharge. The increased OER activities of the metal/ metal oxide composites can be attributed to the accelerated charge transfer (Fig. $5 c$, d) induced by the insitu formed metal phase and the metal/metal oxide interface. These results further indicate that, using the lithium-induced chemical conversion reaction, metal/ metal oxide composites can be in-situ fabricated with abundant metal/metal oxide interfaces and excellent electrical interconnection between the well-dispersed metal nanocrystallines and metal oxide matrix. At the interfaces, metal cations possess positive charge and more unfiled d-orbits, which can facilitate $\mathrm{OH}^{-}$adsorption due to the strong electrostatic interactions. Meanwhile, a nearby metal site would preferentially adsorb $\mathrm{H}$ atom, thus boosting the water electrolysis.

\section{CONCLUSION}

In summary, we demonstrated that metal/metal oxide composite electrocatalysts including $\mathrm{NiCo} / \mathrm{NiCo}_{2} \mathrm{O}_{4}$, $\mathrm{NiMn} / \mathrm{NiMn}_{2} \mathrm{O}_{4}$ and $\mathrm{CoMn} / \mathrm{CoMn} \mathrm{O}_{4}$ with abundant interfaces, excellent electrical interconnection as well as more catalytically active sites can be in-situ fabricated through the lithium-induced conversion reaction, which greatly increase the electrocatalytic OER activities of the metal oxides. For instance, the $3 \mathrm{rd} \mathrm{NiCo} / \mathrm{NiCo}_{2} \mathrm{O}_{4}$ exhibited superior water oxidation properties by attaining an overpotential of $264 \mathrm{mV}$ at $10 \mathrm{~mA} \mathrm{~cm}^{-2}$ with a low Tafel slope of $64 \mathrm{mV} \mathrm{dec}^{-1}$ and excellent long-term stability in alkaline solutions. We further detected that $\mathrm{Ni}$ sites in the $\mathrm{NiCo} / \mathrm{NiCo}_{2} \mathrm{O}_{4}$ composite are the real active centers for OER by in-situ X-ray and Raman spectroscopic tracking. The improved OER activities could be attributed to the synergistic effect of the increased electrochemically active sites and the enhanced charge transfer.

Received 23 April 2020; accepted 2 June 2020;

published online 28 August 2020

1 Jiao Y, Zheng Y, Jaroniec M, et al. Design of electrocatalysts for oxygen- and hydrogen-involving energy conversion reactions. Chem Soc Rev, 2015, 44: 2060-2086 
2 Guo Y, Park T, Yi JW, et al. Nanoarchitectonics for transitionmetal-sulfide-based electrocatalysts for water splitting. Adv Mater, 2019, 31: 1807134

3 Duan J, Chen S, Zhao C. Ultrathin metal-organic framework array for efficient electrocatalytic water splitting. Nat Commun, 2017, 8: 15341

4 Wang $\mathrm{C}, \mathrm{Lu} \mathrm{H}$, Mao Z, et al. Bimetal schottky heterojunction boosting energy-saving hydrogen production from alkaline water via urea electrocatalysis. Adv Funct Mater, 2020, 30: 2000556

5 Huang J, Sun Y, Du X, et al. Cytomembrane-structure-inspired active Ni-N-O interface for enhanced oxygen evolution reaction. Adv Mater, 2018, 30: 1803367

6 Fang M, Dong G, Wei R, et al. Hierarchical nanostructures: Design for sustainable water splitting. Adv Energy Mater, 2017, 7: 1700559

7 Tong Y, Wu J, Chen $\mathrm{P}$, et al. Vibronic superexchange in double perovskite electrocatalyst for efficient electrocatalytic oxygen evolution. J Am Chem Soc, 2018, 140: 11165-11169

8 Lee $\mathrm{Y}$, Suntivich J, May KJ, et al. Synthesis and activities of rutile $\mathrm{IrO}_{2}$ and $\mathrm{RuO}_{2}$ nanoparticles for oxygen evolution in acid and alkaline solutions. J Phys Chem Lett, 2012, 3: 399-404

9 Trotochaud L, Ranney JK, Williams KN, et al. Solution-cast metal oxide thin film electrocatalysts for oxygen evolution. J Am Chem Soc, 2012, 134: 17253-17261

10 Audichon T, Napporn TW, Canaff C, et al. $\mathrm{IrO}_{2}$ coated on $\mathrm{RuO}_{2}$ as efficient and stable electroactive nanocatalysts for electrochemical water splitting. J Phys Chem C, 2016, 120: 2562-2573

11 Han L, Dong S, Wang E. Transition-metal (Co, Ni, and Fe)-based electrocatalysts for the water oxidation reaction. Adv Mater, 2016, 28: 9266-9291

12 Huang J, Sun Y, Zhang Y, et al. A new member of electrocatalysts based on nickel metaphosphate nanocrystals for efficient water oxidation. Adv Mater, 2018, 30: 1705045

13 Paul R, Dai Q, Hu C, et al. Ten years of carbon-based metal-free electrocatalysts. Carbon Energy, 2019, 1: 19-31

14 Sun Z, Wang X, Zhao H, et al. Rambutan-like hollow carbon spheres decorated with vacancy-rich nickel oxide for energy conversion and storage. Carbon Energy, 2020, 2: 122-130

15 Deng $\mathrm{S}$, Shen $\mathrm{Y}$, Xie D, et al. Directional construction of $\mathrm{Cu}_{2} \mathrm{~S}$ branch arrays for advanced oxygen evolution reaction. J Energy Chem, 2019, 39: 61-67

16 Deng S, Zhong Y, Zeng Y, et al. Hollow $\mathrm{TiO}_{2} @ \mathrm{Co}_{9} \mathrm{~S}_{8}$ core-branch arrays as bifunctional electrocatalysts for efficient oxygen/hydrogen production. Adv Sci, 2018, 5: 1700772

17 Qiao C, Rafai S, Cao T, et al. Tuning surface electronic structure of two-dimensional cobalt-based hydroxide nanosheets for highly efficient water oxidation. ChemCatChem, 2020, 12: 2823-2832

18 Souleymen R, Wang Z, Qiao C, et al. Microwave-assisted synthesis of graphene-like cobalt sulfide freestanding sheets as an efficient bifunctional electrocatalyst for overall water splitting. J Mater Chem A, 2018, 6: 7592-7607

19 Zhang B, Zhang X, Wei Y, et al. General synthesis of NiCo alloy nanochain arrays with thin oxide coating: A highly efficient bifunctional electrocatalyst for overall water splitting. J Alloys Compd, 2019, 797: 1216-1223

20 Feng C, Guo Y, Xie Y, et al. Bamboo-like nitrogen-doped porous carbon nanofibers encapsulated nickel-cobalt alloy nanoparticles composite material derived from the electrospun fiber of a bimetalorganic framework as efficient bifunctional oxygen electrocatalysts. Nanoscale, 2020, 12: 5942-5952

21 Liu C, Wang Z, Zong X, et al. N\&S co-doped carbon nanofiber network embedded with ultrafine NiCo nanoalloy for efficient oxygen electrocatalysis and $\mathrm{Zn}$-air batteries. Nanoscale, 2020, 12: 9581-9589

22 Gebremariam TT, Chen F, Jin Y, et al. Bimetallic NiCo/CNF encapsulated in a N-doped carbon shell as an electrocatalyst for $\mathrm{Zn}$ air batteries and water splitting. Catal Sci Technol, 2019, 9: 25322542

23 Zhu YP, Ma TY, Jaroniec M, et al. Self-templating synthesis of hollow $\mathrm{Co}_{3} \mathrm{O}_{4}$ microtube arrays for highly efficient water electrolysis. Angew Chem Int Ed, 2017, 56: 1324-1328

24 Osgood H, Devaguptapu SV, Xu H, et al. Transition metal (Fe, Co, $\mathrm{Ni}$, and $\mathrm{Mn}$ ) oxides for oxygen reduction and evolution bifunctional catalysts in alkaline media. Nano Today, 2016, 11: 601-625

25 Song F, Hu X. Exfoliation of layered double hydroxides for enhanced oxygen evolution catalysis. Nat Commun, 2014, 5: 4477

26 Liang H, Meng F, Cabán-Acevedo M, et al. Hydrothermal continuous flow synthesis and exfoliation of NiCo layered double hydroxide nanosheets for enhanced oxygen evolution catalysis. Nano Lett, 2015, 15: 1421-1427

27 Wang L, Chen H, Daniel Q, et al. Promoting the water oxidation catalysis by synergistic interactions between $\mathrm{Ni}(\mathrm{OH})_{2}$ and carbon nanotubes. Adv Energy Mater, 2016, 6: 1600516

28 Du X, Huang J, Zhang J, et al. Modulating electronic structures of inorganic nanomaterials for efficient electrocatalytic water splitting. Angew Chem Int Ed, 2019, 58: 4484-4502

29 Wang $\mathrm{X}$, Sun $\mathrm{P}, \mathrm{Lu} \mathrm{H}$, et al. Aluminum-tailored energy level and morphology of $\mathrm{Co}_{3-x} \mathrm{Al}_{x} \mathrm{O}_{4}$ porous nanosheets toward highly efficient electrocatalysts for water oxidation. Small, 2019, 15: 1804886

30 Tang T, Jiang WJ, Niu S, et al. Electronic and morphological dual modulation of cobalt carbonate hydroxides by Mn doping toward highly efficient and stable bifunctional electrocatalysts for overall water splitting. J Am Chem Soc, 2017, 139: 8320-8328

31 Huang J, Gao H, Xia Y, et al. Enhanced photoelectrochemical performance of defect-rich $\mathrm{ReS}_{2}$ nanosheets in visible-light assisted hydrogen generation. Nano Energy, 2018, 46: 305-313

32 Ali T, Wang $\mathrm{X}$, Tang $\mathrm{K}$, et al. $\mathrm{SnS}_{2}$ quantum dots growth on $\mathrm{MoS}_{2}$ : Atomic-level heterostructure for electrocatalytic hydrogen evolution. Electrochim Acta, 2019, 300: 45-52

33 Gong M, Zhou W, Tsai MC, et al. Nanoscale nickel oxide/nickel heterostructures for active hydrogen evolution electrocatalysis. Nat Commun, 2014, 5: 4695

34 Yan X, Tian L, He M, et al. Three-dimensional crystalline/amorphous $\mathrm{Co} / \mathrm{Co}_{3} \mathrm{O}_{4}$ core/shell nanosheets as efficient electrocatalysts for the hydrogen evolution reaction. Nano Lett, 2015, 15: 60156021

35 Wang $\mathrm{X}$, Xiao $\mathrm{H}$, Li A, et al. Constructing $\mathrm{NiCo} / \mathrm{Fe}_{3} \mathrm{O}_{4}$ heteroparticles within MOF-74 for efficient oxygen evolution reactions. J Am Chem Soc, 2018, 140: 15336-15341

36 Zhang J, Wang T, Liu P, et al. Efficient hydrogen production on $\mathrm{MoNi}_{4}$ electrocatalysts with fast water dissociation kinetics. Nat Commun, 2017, 8: 15437

37 Chen YY, Zhang Y, Zhang X, et al. Self-templated fabrication of $\mathrm{MoNi}_{4} / \mathrm{MoO}_{3-x}$ nanorod arrays with dual active components for highly efficient hydrogen evolution. Adv Mater, 2017, 29: 1703311

38 Wang J, Xu F, Jin $\mathrm{H}$, et al. Non-noble metal-based carbon composites in hydrogen evolution reaction: Fundamentals to applications. Adv Mater, 2017, 29: 1605838

39 Lu Z, Wang H, Kong D, et al. Electrochemical tuning of layered lithium transition metal oxides for improvement of oxygen evolution reaction. Nat Commun, 2014, 5: 4345 
40 Liu Y, Wang H, Lin D, et al. Electrochemical tuning of olivine-type lithium transition-metal phosphates as efficient water oxidation catalysts. Energy Environ Sci, 2015, 8: 1719-1724

41 Lu Z, Chen G, Li Y, et al. Identifying the active surfaces of electrochemically tuned $\mathrm{LiCoO}_{2}$ for oxygen evolution reaction. J Am Chem Soc, 2017, 139: 6270-6276

42 Wang $\mathrm{H}, \mathrm{Lu} \mathrm{Z}, \mathrm{Xu} \mathrm{S}$, et al. Electrochemical tuning of vertically aligned $\mathrm{MoS}_{2}$ nanofilms and its application in improving hydrogen evolution reaction. Proc Natl Acad Sci USA, 2013, 110: 1970119706

43 Zhang X, Luo Z, Yu P, et al. Lithiation-induced amorphization of $\mathrm{Pd}_{3} \mathrm{P}_{2} \mathrm{~S}_{8}$ for highly efficient hydrogen evolution. Nat Catal, 2018, 1: $460-468$

44 Wang H, Xu S, Tsai C, et al. Direct and continuous strain control of catalysts with tunable battery electrode materials. Science, 2016, 354: 1031-1036

45 Wang H, Lee HW, Deng Y, et al. Bifunctional non-noble metal oxide nanoparticle electrocatalysts through lithium-induced conversion for overall water splitting. Nat Commun, 2015, 6: 7261

46 Chen $\mathrm{S}, \mathrm{Wu} J$, Zhou $\mathrm{R}$, et al. Controllable growth of $\mathrm{NiCo}_{2} \mathrm{O}_{4}$ nanoarrays on carbon fiber cloth and its anodic performance for lithium-ion batteries. RSC Adv, 2015, 5: 104433

47 Shen $\mathrm{L}$, Che $\mathrm{Q}, \mathrm{Li} \mathrm{H}$, et al. Mesoporous $\mathrm{NiCo}_{2} \mathrm{O}_{4}$ nanowire arrays grown on carbon textiles as binder-free flexible electrodes for energy storage. Adv Funct Mater, 2014, 24: 2630-2637

48 Xie $\mathrm{Y}$, Wang $\mathrm{X}$, Tang $\mathrm{K}$, et al. Blending $\mathrm{Fe}_{3} \mathrm{O}_{4}$ into a $\mathrm{Ni} / \mathrm{NiO}$ composite for efficient and stable bifunctional electrocatalyst. Electrochim Acta, 2018, 264: 225-232

49 Yan X, Li KX, Lyu L, et al. From water oxidation to reduction: Transformation from $\mathrm{Ni}_{x} \mathrm{Co}_{3-x} \mathrm{O}_{4}$ nanowires to $\mathrm{NiCo} / \mathrm{NiCoO}_{x}$ heterostructures. ACS Appl Mater Interfaces, 2016, 8: 3208-3214

$50 \mathrm{Hu} \mathrm{C}, \mathrm{Ma} \mathrm{Q}$, Hung SF, et al. In situ electrochemical production of ultrathin nickel nanosheets for hydrogen evolution electrocatalysis. Chem, 2017, 3: 122-133

$51 \mathrm{Ma} \mathrm{Q}, \mathrm{Hu} \mathrm{C}$, Liu K, et al. Identifying the electrocatalytic sites of nickel disulfide in alkaline hydrogen evolution reaction. Nano Energy, 2017, 41: 148-153

52 Yin J, Li Y, Lv F, et al. Oxygen vacancies dominated $\mathrm{NiS}_{2} / \mathrm{CoS}_{2}$ interface porous nanowires for portable $\mathrm{Zn}$-Air batteries driven water splitting devices. Adv Mater, 2017, 29: 1704681

53 Su X, Wang Y, Zhou J, et al. Operando spectroscopic identification of active sites in NiFe prussian blue analogues as electrocatalysts: Activation of oxygen atoms for oxygen evolution reaction. J Am Chem Soc, 2018, 140: 11286-11292

54 Jiang J, Sun F, Zhou S, et al. Atomic-level insight into superefficient electrocatalytic oxygen evolution on iron and vanadium co-doped nickel (oxy)hydroxide. Nat Commun, 2018, 9: 2885

55 Wang HY, Hsu YY, Chen $\mathrm{R}$, et al. $\mathrm{Ni}^{3+}$-induced formation of active $\mathrm{NiOOH}$ on the spinel Ni-Co oxide surface for efficient oxygen evolution reaction. Adv Energy Mater, 2015, 5: 1500091

56 Padmanathan N, Selladurai S. Controlled growth of spinel $\mathrm{NiCo}_{2} \mathrm{O}_{4}$ nanostructures on carbon cloth as a superior electrode for supercapacitors. RSC Adv, 2014, 4: 8341-8349

57 Yang X, Yu X, Yang Q, et al. Controllable synthesis and magnetic properties of hydrothermally synthesized $\mathrm{NiCo}_{2} \mathrm{O}_{4}$ nano-spheres. Ceramics Int, 2017, 43: 8585-8589

58 Zhu K, Zhu X, Yang W. Application of in situ techniques for the characterization of NiFe-based oxygen evolution reaction (OER) electrocatalysts. Angew Chem Int Ed, 2019, 58: 1252-1265
Acknowledgements This work was supported by the National Natural Science Foundation of China (21603157), and Young Elite Scientists Sponsorship Program by CAST (2018QNRC001). We also thank the support of Suzhou Key Laboratory for Advanced Carbon Materials and Wearable Energy Technologies and Soochow University Analysis and Testing Center.

Author contributions Wang C, Yan C and Wang X conceived the idea and designed the experiment; Wang C, Khan S, Lu H, Cao Y and Mao Z carried out the syntheses, characterizations, electrochemical experiments and calculation. All authors participated in the data analyses and contributed to the manuscript writing.

Conflict of interest The authors declare that they have no conflict of interest.

Supplementary information Caculation methods and supporting data are available in the online version of the paper.

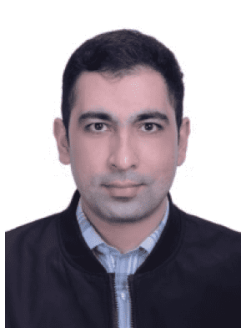

Shahid Khan is a master student under the supervision of Prof. Chenglin Yan and Prof. Xianfu Wang at the School of Energy, Soochow University. His research interest focuses on the synthesis and application of functional nanomaterials for electrochemistry fields.

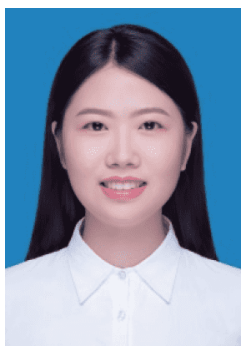

Chao Wang obtained her master degree from the School of Energy, Soochow University. Her research interest focuses on the electro-/photocatalysis, and flexible/wearable energy storage.

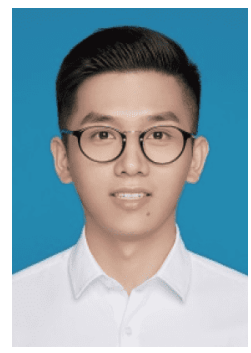

Haoliang $\mathbf{L u}$ is a master student under the supervision of Prof. Chenglin Yan at the School of Energy, Soochow University. His research interest focuses on zinc-ion batteries, graphene energy storage and its applications. 


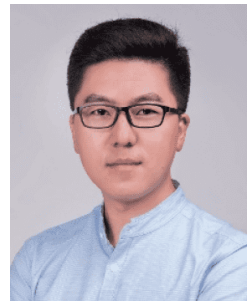

Xianfu Wang received his $\mathrm{PhD}$ degree in physical electronics from Huazhong University of Science and Technology in 2015. He is now a distinguished professor at the University of Electronic Science and Technology of China. His current research interests focus on low-dimensional functional materials and fundamental principles in energy conversion/storage, nanoelectronics, and optoelectronics.
原位相转化反应制备的金属/金属氧化物用于析 氧反应

Shahid $\operatorname{Khan}^{1 \dagger}$, 王超 ${ }^{1 \dagger}$, 陆豪量 ${ }^{1 \dagger}$, 曹宇锋 ${ }^{*}$, 冒泽阳 ${ }^{1}$, 晏成林 ${ }^{1^{*}}$, 王显福 ${ }^{2 *}$

摘要 金属/金属氧化物复合材料凭借其独特的界面和电子结构已 被广泛设计合成, 并应用于碱性溶液中电催化析氧反应的电催化 剂. 然而, 如何设计并获得丰富的金属/金属氧化物界面和均匀分 散的金属相仍是一个挑战. 此外, 金属和金属氧化物在增强电催化 活性方面的协同机理依然不清晰. 本文以金属氧化物为基体, 通过 锂诱导的转化反应, 制备了具有丰富界面和优异电接触的金属/金 属氧化物复合物, 增加了催化活性位点, 并加速了电催化反应过程 中的传质. 利用该方法制备出的 $\mathrm{NiCo} / \mathrm{NiCo}_{2} \mathrm{O}_{4}, \mathrm{NiMn} / \mathrm{NiMn}_{2} \mathrm{O}_{4}$ 和 $\mathrm{CoMn} / \mathrm{CoMn}_{2} \mathrm{O}_{4}$ 催化剂的析氧性能有显著提升. 通过原位X射线吸 收光谱和原位拉曼光谱技术, 本文探索了复合催化剂的催化机理, 揭示了析氧反应中的催化活性中心以及金属与金属氧化物之间的 协同作用机理. 密度泛函理论 $+\mathrm{U}(\mathrm{DFT}+\mathrm{U})$ 计算证实了金属/金属 氧化物材料中的金属组分可以优化催化反应路径并降低反应势垒, 从而加速电催化动力学. 